Nunt. Antiquus, Belo Horizonte, v. 15, n. 2, p. 159-176, 2019

\title{
Os fragmentos de Varrão Atacino: tradução e notas
}

\author{
Varro Atacinus' Fragments: Translation and Notes
}

\author{
Jéssica Frutuoso Mello \\ Universidade Federal de Alfenas (UNIFAL), Alfenas, Minas Gerais / Brasil \\ jessicafrutuoso.m@gmail.com
}

Resumo: Apresenta-se a tradução para o português dos fragmentos das obras de Varrão Atacino - Argonautas, Topografia, Notas e Guerra Sequana -, precedida de uma breve introdução sobre o autor. Varrão é um poeta sobre o qual pouco se sabe, e as poucas informações que restam são questionáveis. Infelizmente, processo semelhante ocorre com sua obra, que foi quase inteiramente perdida, restando apenas 26 fragmentos. A tradução realizada prioriza o sentido do texto. Constam, em notas de rodapé, comparações das edições consultadas, assim como possíveis equivalências aos trechos das obras de Apolônio de Rodes e Arato, já que seus poemas Argonautas e Notas seriam traduções daquelas, respectivamente.

Palavras-chave: Varrão Atacino; Argonautas; Topografia; Notas; Guerra Sequana.

Abstract: A Portuguese translation of the fragments of the works of Varro Atacinus - Argonautae; Chrorographia; Ephemeris and Bellum Sequanicum - is presented, preceded by a brief introduction about the author. Varro is a poet about whom little is known, and the little information left is questionable. Unfortunately, a similar process occurs with his work, which was almost entirely lost: only 26 fragments survived. The current translation defines the meaning of the text as priority. In addition, there are comparisons of the consulted editions in the footnotes, as well as possible equivalences to the excerpts of the works of Apollonius of Rhodes and Aratus, since his poems Argonautae and Ephemeris would be translations of the works of the same name by Atacinus.

Keywords: Varro Atacinus; Argonautae; Chrorographia; Ephemeris; Bellum Sequanicum. 
Públio Terêncio Varrão - ou Varrão Atacino - foi um poeta do século I a.C. Das poucas informações que se tem a seu respeito, Jerônimo apresentaria em suas Crônicas: "P. Terêncio Varrão nasce na aldeia de Atax, na província Narbonense, ele que, depois de vividos trinta e cinco anos, aprendeu as letras gregas com extrema dedicação"1 (Chro., CLXIII Olympias, 7, g, tradução nossa). Porém, esses dados são questionados por estudiosos como Courtney (2003) e Crowter (1987) que apontam inconsistências em relação ao nome da aldeia em que Jerônimo afirma que Varrão teria nascido (COURTNEY, 2003, p. 235-236) e a possibilidade de conhecimento do grego pelo poeta, devido à riqueza de sua família ou à região em que teria vivido (CROWTER, 1987, p. 264-265).

Em relação a suas obras, Varrão Atacino foi um autor que aderiu à seriedade de Ênio, com um poema épico (Bellum Sequanicum), sobre a campanha de César em 58 a.C., mas que também explorou temas menores em sua elegia erótica (Elegia). Ademais, dedicou-se, ao que parece, à sátira (Saturae), além da tradução de autores gregos, tendo realizado a tradução total da epopeia de Apolônio de Rodes, em seus Argonautae (POLT, 2013, p. 607-608), e as parciais de Erastótenes, em seu poema didático Chorographia, e dos Phaenomena de Arato, em seu Epimenis ${ }^{2}$ (LEE, 1996, p. 36). Infelizmente, restaram apenas alguns fragmentos de suas obras, assim como o juízo de outros autores, como Horácio, ${ }^{3}$ Ovídio, ${ }^{4}$

1 "P. Terentius Varro uico Atace in prouincia Narbonensi nascitur, qui postea XXXV [XXV cod. unus] annum agens Graecas litteras cum summo studio didicit" (Hier., Chro., 143 Olympias, 7, g apud COURTNEY, 2003, p. 235).

${ }^{2}$ Ou Ephemeris (GAYRAUD, 1971, p. 655).

3 "hoc erat, experto frustra Varrone Atacino / atque quibusdam aliis, melius quod scribere possem, / inuentore minor; [...]" (Hor., S., 1, 10, 46-49). "Só podia na sátira, debalde / Por Varrão já tentada, e vários outros, / Abaixo do inventor assinalar-me" (Hor., S., 1, 10, 46-48, tradução de A. L. Seabra).

4 "Varronem primamque ratem quae nesciet aetas, / Aureaque Aesonio terga petita duci?" (Ov., Am., 1, 15, 21-22). "Que época ignorará Varrão e a prima barca; / velo de ouro que o Esônio resgatou?" (Ov., Am., 1, 15, 21-22, tradução de G. H. Duque). "Dictaque Varroni fuluis insignia uilis / Vellera, germanae, Phrixe, querenda tuae:" (Ov., Ars am., 3, 335-336). "O Varrão, quando vos canta auriluzente pele / do animal, vinda de Frixo, horrenda morte de Hele;" (Ov., Ars am., 3, 335-336, tradução de A. Feliciano de Castilho). 
Propércio, ${ }^{5}$ Sêneca, o Velho ${ }^{6}$ e Quintiliano, ${ }^{7}$ além de citações diretas de Virgílio. ${ }^{8}$ Embora sua tradução da epopeia de Apolônio de Rodes tenha desfrutado de fama, isso não ocorre com seu primeiro poema épico, que

"is quoque, Phasiacas Argon qui duxit in undas, / non potuit Veneris furta tacere suae." (Ov., Tr. 2, 439-440). "Mesmo aquele que nas ondas do Faso conduziu Argos / Não pôde calar seus amores furtivos." (Ov., Tr., 2, 439-440, tradução de P. Prata).

5 "haec quoque perfecto ludebat Iasone Varro, / Varro Leucadiae maxima flamma suae," (Prop., 2, 34, 85-86). "Varrão também louvava essa poesia, acabado seu Jasão, / Varrão, a maior flama de sua Leocádia;" (Prop., 2, 34, 85-86, tradução de P. Martins). 6 "Montanus Iulius, qui comes fuit $<$ Tiberii $>$, egregius poeta, aiebat illum imitari uoluisse Vergili descriptionem: nox erat et terras animalia fessa per omnis, alituum pecudumque genus, sopor altus habebat. At Vergilio imitationem bene cessisse, qui illos optimos uersus Varronis expressisset in melius: desierant latrare canes urbesque silebant; omnia noctis erant placida composta quiete. Solebat Ouidius de his uersibus dicere potuisse fieri longe meliores si secundi uersus ultima pars abscideretur et sic desineret: omnia noctis erant. Varro quem uoluit sensum optime explicuit, Ouidius in illius uersu suum sensum inuenit; aliud enim intercisus uersus significaturus est, aliud totus significat." (Sen., Con., 7, 1, 10-25). "Júlio Montano, poeta notável, que foi amigo de Tibério, afirmava que ele [Céstio] queria imitar uma descrição de Virgílio: 'era noite e, por toda terra, um sono profundo guardava os cansados animais, as espécies de aves e de rebanhos'. Mas, a imitação teria saído bem a Virgílio, porque moldou, em algo melhor, esses ótimos versos de Varrão: 'os cães cessaram de latir e as cidades silenciavam: tudo estava sossegado no repouso tranquilo da noite'. Sobre esses versos, Ovídio costumava dizer que podiam tornar-se de longe melhores se a última parte do segundo verso fosse cortada e acabasse assim: 'tudo o que havia é da noite'. Varrão, que desejou [alcançar] um sentido, explicou de modo ótimo; Ovídio no verso dele [Varrão] encontrou o seu próprio sentido; de fato, algo que o verso cortado era digno de significar, outra coisa, inteiro está significando." (Sen., Con., 7, 1, 10-25, tradução nossa). Os versos de Virgílio citados são os 26 e 27 do livro 8 da Eneida. José Victorino Barreto Feio traduz: "Era noite; e por toda a redondeza, / Os lassos animais, aves e brutos, / Vencidos d'alto sono descansavam:" (Verg., A., 8, 26-27).

7 "atacinus Varro in iis, per quae nomen est adsecutus, interpres operis alieni, non spernendus quidem, uerum ad augendam facultatem dicendi parum locuples." (Quint., Inst., 10, 87). "Varrão de Atax alcançou renome justamente na condição de intérprete de obra alheia. Ele não deve ser desprezado, mas, na verdade, para se desenvolver a capacidade oratória ele oferece poucos recursos." (Quint., Inst., 10, 87, tradução de A. M. Resende).

${ }^{8} \mathrm{Cf}$. notas 23 e 45 . 
só teria sido citado uma única vez, por Prisciano 9 (GAYRAUD, 1971, p. 652) - supostamente o único fragmento da obra que resta ${ }^{10}$-, e nem com suas sátiras, dado o comentário de Horácio. De sua obra elegíaca, além da informação de que era dedicada a sua Leucádia, nada sobreviveu. ${ }^{11}$

Aqui, são propostas traduções dos fragmentos de Varrão, dando ênfase ao sentido do texto, a partir das lições latinas oferecidas principalmente pela edição de Baehrens (1886), tendo sido esta comparada com as edições de Blänsdorf (2011), Courtney (2003) e Hollis (2007). Pretende-se que a opção pela edição de Baehrens (1886) permita ao leitor ter um panorama das edições dos fragmentos de Varrão Atacino, partindo de uma mais antiga, já que as notas de rodapé trazem comentários acerca, principalmente, de diferenças encontradas nas edições consultadas. Sua ausência indica que o fragmento aparece do mesmo modo em todas essas edições. Os números que antecedem os fragmentos dizem respeito à numeração de Baehrens (1886); sua falta indica a ausência do fragmento na edição, e a inserção ou o deslocamento de um fragmento é justificado em nota de rodapé. Opta-se por uma tradução em prosa, o que, supostamente, permite uma maior liberdade tradutória, principalmente pela falta de restrições ligadas à métrica. Busca-se, de modo geral, não criar um estranhamento maior no leitor do que aquele que já poderia ser causado pelo próprio texto em seu caráter fragmentário.

Foram colocadas também, em notas de rodapé e sempre que possível, as passagens do poema de Apolônio de Rodes, utilizando a tradução de José Maria da Costa e Silva (1852), apontadas como equivalentes às dos Argonautas, e as do texto de Arato, a partir da tradução de Rafael Matiello Brunhara et al. (2016), correspondentes às da Topografia.

9 "P. Varro belli Sequanici libro II: Deinde ubi pellicuit dulcis leuis unda saporis." (Prisc., 10). "P. Varrão, no segundo livro de Guerra Sequana: 'depois, quando a leve água de doce sabor atraiu."” (Tradução nossa).

${ }^{10} \mathrm{Cf}$. nota 31 , onde discute-se se o fragmento 10 também faria parte da obra.

${ }^{11}$ Embora, cf. nota 25, Baehrens (1886, p. 336) atribua o fragmento 24 à Elegia, há um consenso de que ele pertença aos Argonautae (GAYRAUD, 1971, p. 659). 


\section{Argonautae: Os Argonautas}

\subsection{LIB. I: Livro I}

1 ecce uenit Danai multis celebrata propago;

namque satus Clytio, Lerni quem Naubolus ex se, Lernum Naupliades Proteus, sed Nauplion edit

filia Amymone Europae Danaique superbi. ${ }^{12}$

eis que veio a raça de Dânao, celebrada por muitos; e, realmente, gerada de Clítio, este de Náubolo, filho de Lerno, Lerno de Proteu Naplíada, mas Amimone, filha de Europa e do soberbo Dânao, dá à luz a Náuplio. ${ }^{13}$

2 Tiphyn at aurigam celeris fecere carinae. ${ }^{14}$

mas fizeram Tífis auriga da célere nau. ${ }^{15}$

3 quos magno Anchiale partus adducta dolore et geminis capiens tellurem Oaxida palmis edidit in Dicta. ${ }^{16}$

${ }^{12}$ Em Blänsdorf (2011, p. 232), em Courtney (2003, p. 239) e em Hollis (2007, p. 172), o termo é Proetus, que pode ser traduzido como "Preto", mais próximo do termo grego, Прoítov (Proitoy).

13 "Com estes vinha Nauplio, em cujas veias / Corre o sangue de Danao, pois contava / A Clitoneo por Pae: Clitoneo filho / De Naubulo, de Lerno filho, e Lerno / De Preto, que outro Naubulo gerara. / E depois que Neptuno em braços teve / Filha de Dánao, Amimome paríra / Nauplio, [...]" (A. R., 1, 133-140, tradução de J. M. da Costa e Silva). ${ }^{14}$ Em Blänsdorf (2011, p. 232) e Hollis (2007, p. 172): "2 Tiphyn <et > aurigam celeris fecere carinae." Courtney (2003, p. 239) não apresenta et ou at, sendo sua escolha criticada por Hollis (2007, p. 200).

15 "Depois por votos incumbiram Typhis / Do governo do leme. [...]" (A. R., 1, 400401, tradução de J. M. da Costa e Silva).

16 Em Blänsdorf (2011, p. 233): "3 quos magno Achiale partus adducta dolore / et geminis cupiens tellurem Oeaxida palmis / scindere Dicta <eo ...>." Em Courtney (2003, p. 240): "5 quos magno Achiale partus adducta dolore / et geminis cupiens tellurem $O<e>$ axida palmis / scindere Dicta $<$ eo quondam est enixa sub antro. $>$." E em Hollis (2007, p. 173): "125 quos magno Achiale partus adducta dolore / et geminis cupiens tellurem Oeaxida palmis / scindere Dicta <eo vu_vu nympha sub antro>.", embora ofereça a possibilidade de "scindere, Dictaeo profudit nympha sub antro.>" (HOLLIS, 2007, p. 202). Além disso, considera que a utilização de capiens ocorre, pois cupiens, "desejando", torna o texto truncado e ininteligível (HOLLIS, 2007, p. 202). 
aos quais, Anquíale, levada pela grande dor do parto, agarrando a terra eácida com as duas mãos, deu à luz no Dicta. ${ }^{17}$

\subsection{LIB. II: Livro II}

4 Probus ad Verg. G. I 14: ibi (in insula Cea) existimatur pestilentia fuisse pecorum et armentorum grauis propter interitum Actaeomis. Aristaeus monstrante Apolline patre profectus est in insulam Ceam et ibi sacrificio facto aram Ioui Icmaeo constituit, qui placatis flatibus et aestu, qui necabant pecora et armenta, liberauit ea. ipse autem post excessum uitae imperante oraculo Apollinis ab inmorantibus in ea insula relatus in numerum deorum appellatus est Nomius et Aegoros, quod et agresti studio et cura pecorum armentorumque non mediocriter profuerat hominibus. traditur haec historia de Aristaeo in corpore Argonautarum a Varrone Atacino. (Cf. Apoll. Rhod. II 500 et seq.). ${ }^{18}$

Probo nas Geórgicas $(1,14){ }^{19}$ de Virgílio: Ali (na ilha Cea) é julgado ter havido uma grave pestilência aos gados e aos rebanhos por causa da morte de Acteão. Aristeu, com seu pai Apolo indicando, dirigiu-se à ilha Cea, e ali, feito um sacrifício, construiu um altar para Jove Icmaeu, que, tendo aplacado as aragens e o calor que matavam gados e rebanhos, os libertou. Ele, no entanto, após a morte, por ordem do oráculo de Apolo, tendo sido levado pelos imortais àquela ilha, estando entre eles, foi chamado Nômio e Egoro, porque não pouco tinha sido benéfico aos homens, seja pelo zelo com o campo, seja pelo cuidado dos gados e rebanhos. Essa história de Aristeu é transmitida no corpo dos Argonautas por Varrão Atacino. ${ }^{20}$

17 ' “[...] e que em Dictea gruta / Outr'ora a Nympha Anchiale, as mãos ambas / Ferrando a terra Oaxide, paríra." (A. R., 1, 1229-1231, tradução de J. M. da Costa e Silva).

${ }^{18}$ Em Blänsdorf (2011, p. 233) e em Hollis (2007, p. 174, grifo nosso), há “[...] ipse autem post excessum uitae imperante oraculo Apollinis ab inhabitantibus eam insulam relatus in numerum deorum [...]". Courtney (2003, p. 241) apresenta apenas a última parte do trecho.

19 "[...] Et cultor nemorum cui pinguia Ceae / Ter centum niuei tondent dumenta iuuenci," (Verg., Georg., 1, 14-15). José Félix Pereira (1875, p. 2) traduz: "E tu, cultor das selvas, que possues / Trezentos níveos touros, que pascendo / Andão de Cea os abundosos matos:".

20 “" [...] alli de Apollo / Pariu ella Aristeo, a quem nomeia / Agreste, e Pastoral a Hermonia Gente / Opulenta em Searas. [...] / Quando as Ilhas Minoidas retisnava / Syrio ardendo nos Céos, e os Moradores / Sem remedio encontrar ha muito estavam, / Por conselho 
5 te nunc Coryciae tendentem spicula nymphae hortantes "o Phoebe" et "ieie" conclamarunt. ${ }^{21}$

agora, as ninfas corícias, que instigam a ti, o que estende flechas, gritaram "ó, Febo" e "ie-iê". ${ }^{22}$

6 frigidus et siluis aquilo decussit honorem. ${ }^{23}$

$\mathrm{E}$, nas florestas, Aquilão frio derrubou os adereços. ${ }^{24}$

\subsection{LIB. III: Livro III}

24 huic similis curis experdita lamentatur ${ }^{25}$

semelhante a ela, lamenta, toda perdida em cuidados ${ }^{26}$

de Apollo o convocaram / Para os livrar do mal; obedecendo / Aos preceitos do Pae, deixada Phthia, / Veio habitar em Céo; comsigo trouxe / Prole de Lycaon, Arcadias gentes, / Que juntara, e fundou mui grande Templo / Ao chuvi-fero Jove; e sacrifícios / A estrella Syrio celebrou nos Montes, / E ao proprio Jove de Saturno filho. / Por tal causa esse Deos manda que a Terra / As Virações Etesias refrigerem / Dias quarenta, e em Céo os Sacerdotes, / Ao nascer da Canicula, offerecem / Em holocausto annual victimas sacras.” (A. R., 2, 505-526, tradução de J. M. da Costa e Silva).

${ }^{21}$ Hollis (2007, p. 174) apresenta o termo tunc, "naquele momento", no lugar de nunc, justificando que o canto ocorrera naquela ocasião, e que a utilização de " $\mathrm{t}$ " no lugar de "n" gera uma aliteração com "c" (HOLLIS, 2007, p. 205). Assinala também a possibilidade de tum para evitar a colisão entre os sons de [k] (HOLLIS, 2007, p. 205). 22 "Corycias Nymphas, Plistica progenie, / Hyés! Hyés! clamorando te animavam! / Foi d'aqui que este cantico formoso / De Apollo em honra origem teve!'” (A. R., 2, 710-713, tradução de J. M. da Costa e Silva).

${ }^{23}$ Virgílio utiliza este verso em suas Geórgicas (SÁNCHEZ; PRENERÓN, 1989, p. 139). João Félix Pereira traduz: "E lhe tira o aquilão a formosura" (Verg., Georg., 2, 404). 24 “[...] Nas montanhas / Elle apenas moveu brandispirante / Um pouco as folhas nos mais altos ramos." (A. R., 2, 1099-1100, tradução de J. M. da Costa e Silva).

${ }^{25}$ A edição de Baehrens (1886, p. 336) é a única a colocar este fragmento como parte de Elegia: "24 huic similis curis ex petra lamentatur." Contudo, as edições de Blänsdorf (2011, p. 234), de Courtney (2003, p. 242), de Hollis (2007, p. 175), assim como Polt (2013, p. 623), e Sánchez e Prenerón (1989, p. 1397), em seus artigos, o colocam nesta localização, com esta grafia.

26 “Tal lamenta Medea, [...]” (A. R., 3, 664, tradução de J. M. da Costa e Silva). 
7 desierant latrare canes urbesque silebant:

omnia noctis erant placida composta quiete.

os cães cessaram de latir, e as cidades silenciavam: tudo estava sossegado no repouso tranquilo da noite. ${ }^{27}$

8 cuius ut aspexit torta caput angue reuinctum. ${ }^{28}$

quando viu a cabeça dela atada por contorcida cobra..$^{29}$

\subsection{LIB. IV: Livro IV}

9 tum te flagranti deiectum fulmine, Phaethon.

então, tu, Faetonte, derrubado por raio ardente. ${ }^{30}$

10 semianimesque micant oculi lucemque requirunt. ${ }^{31}$

27 “Já em toda a Cidade não se escuta / Ladrar de Cães, sonoro borburinho, / Tudo em pleno silencio abrangem trevas" (A. R., 2, 749-750, tradução de J. M. da Costa e Silva). ${ }_{28}$ Courtney (2003, p. 253) e, segundo Hollis (2007, p. 209), Zetzel inserem este fragmento como parte de Chorographia.

29 "Horrorosas serpentes enlaçadas / Em ramos de carvalho a fronte lhe ornam." (A. R., 3, 1214-1215, tradução de J. M. da Costa e Silva).

30 "Que de Phaetonte fumegante exhala" (A. R., 4, 597-598, tradução de J. M. da Costa e Silva).

${ }^{31}$ Courtney (2003, p. 238) aponta que o fragmento parece mais adequado a uma morte em batalha do que a de Mopso, sendo provavelmente pertencente à obra Bellum Sequanicum. A edição de Blänsdorf (2011, p. 234), assim como Courtney, também situa o fragmento na obra Bellum Sequanicum, no livro 2, embora aponte o possível paralelo com Apolônio. Hollis (2007, p. 166) endossa a localização em Bellum Sequanicum, todavia, indica que seja incerto o livro a que pertença dentro da obra. Como afirma Gayraud (1971, p. 651), o verso aparece nos Anais de Ênio: "320 oscitat in campis caput a ceruice reuolsum / semianimesque micant oculi lucemque requirunt" (apud NATIVIDADE, 2009, p. 205). Everton Natividade (2009, p. 205, grifo nosso) traduz: "separada do pescoço, a cabeça, no campo, abre a boca / e, semimortos, brilham os olhos e buscam a luz." Conforme apontam Edwardes e Wheeler (1845, p. 426), parte dele também aparece em Virgílio, na Eneida (10, 396, grifo nosso): "semianimesque micant digiti ferrumque retractant." José Maria da Costa e Silva (2004, p. 322, grifo nosso) traduz: "[...] e semi-ânimes os dedos / Inda se movem, inda o ferro apertam." 
e os moribundos olhos [se] agitam e buscam a luz. ${ }^{32}$

19 feta feris Libye. ${ }^{33}$

fecunda de feras, Líbia. ${ }^{34}$

\subsection{Incertae Sedis: De localização incerta}

11 Probus ad Georg. II 126: pars Parthorum Media est appellata a Medo, filio Medeae et Aegei, ut existimat Varro, qui quattuor libros de Argonautis edidit. $^{35}$

Probo nas Geórgicas $(2,126):{ }^{36}$ parte do território dos partos foi nomeada "Média" a partir de Medo, filho de Medeia e Egeu, como considera Varrão, que publicou quatro livros sobre os Argonautas.

\footnotetext{
32 "E os membros lhe desata: ja nos olhos" (A. R., 4, 1525, tradução de J. M. da Costa e Silva).

${ }^{33}$ Baehrens (1886, p. 335) coloca este fragmento como parte da obra Chorographia, mas indica, em nota de rodapé, a opção de Wernsdorf por inseri-lo neste ponto dos Argonautae. Blänsdorf (2011, p. 238) e Hollis (2007, p. 169) também situam o fragmento em Chorographia, apontando o possível paralelo com Apolônio de Rodes. Sánchez e Prenerón $(1989$, p. 1397) consideram ser uma tradução para o trecho indicado, afirmando: "El primero en adscribir este breve fragmento a los Argonautae fue RUHNKEN, a quien sigue MOREL. Pero WERNSDORF considero que pertenecía a la Chorographia (como continuación del fr. 19M); y ni TRAGLIA (op. cit., p. 97) ni GRANAROLO (A.N.R.W. I.3, 1973, p. 359) se deciden entre ambas opciones, inscribiéndolo como fragmento incertae sedis." A partir disso e da proximidade com o verso grego, opta-se por sua inserção no canto 4 .

34 “[...] Libia / Terra abundante em feras, [...]” (A. R., 4, 1561, tradução de J. M. da Costa e Silva).

${ }^{35}$ Conforme afirma Courtney (2003, p. 253), esse trecho não pode ser encontrado em Apolônio de Rodes. Para o estudioso, parece claro que esse fragmento pertença à Chorographia, o que também ocorre nas edições de Blänsdorf (2011, p. 239) e de Hollis (2007, p. 170).

36 "Media fert tristes succos tardumque saporem / Felicis mali. [...]" (Verg., Georg., 1, 126-127). José Félix Pereira (1875, p. 29) traduz "Amargo suco de sabor durável / Média produz d'um pomo afortunado."
} 


\section{Chorographia: Topografia}

12 uidit et aetherio mundum torquerier axe et septem aeternis sonitum dare uocibus orbes nitentes aliis alios, quae maxima diuis laetitiast. at tunc longe gratissima Phoebi dextera consimiles meditatur reddere uoces. ${ }^{37}$ viu o mundo ser curvado no eixo celeste, e sete orbes brilhando uns aos outros darem som às vozes eternas, o que, aos deuses, é a máxima alegria. Mas então, longamente, a gratíssima direita de Febo pratica restituir símiles vozes.

13 ergo inter solis stationem et sidera septem exporrecta iacet tellus; huic extima fluctu Oceani, interior Neptuno cingitur ora.

Pois, entre o poente solar e as sete estrelas, a terra jaz estendida; para esta, o litoral mais externo é envolto pela onda do Oceano, o mais interno, por Netuno.

14 at quinque aethereis zonis accingitur orbis, ac uastant imas hiemes mediamque calores: sic terrae extremas inter mediamque coluntur, quas solis rabido numquam uis adterat igne. ${ }^{38}$

Mas o orbe é coberto por cinco zonas celestes, de modo que os invernos assolam os extremos, e os calores, o meio: assim as terras são habitadas no espaço entre suas extremidades e o meio; em que, a força do sol, com violento fogo, nunca diminui.

15 Europam Libyamque rapax ubi diuidit unda. ${ }^{39}$

Onde a onda impetuosa divide a Europa e a Líbia.

\footnotetext{
${ }^{37}$ Courtney (2003, p. 248) também traz “laetitiast”. Em Blänsdorf (2011, p. 236) e em Hollis (2007, p. 167), "laetitia est. [...]".

${ }^{38}$ Em Blänsdorf (2011, p. 236), "qua solis ualido numquam uis ferueat igne." Courtney (2003, p. 250) coloca "†ंnumquam ut†" no último verso. Hollis (2007, p. 167) começa o fragmento com $u t$ no lugar de at $\mathrm{e}$ traz "[...] nunquam †ut auferat $\dagger$ igne." no último verso. ${ }^{39}$ Blänsdorf (2011, p. 241) apresenta este fragmento como Dubia. As edições de Courtney (2003) e de Hollis (2007) não contêm esse fragmento.
} 
$16-\cup \cup-\cup \cup-$ tutum sub sede fuissent.

... seguro, estivessem sob a morada.

17 munitus uicus Caralis $\cup \cup-\cup \cup--$

Carale, aldeia fortificada...

18 cingitur oceano, Libyco mare, flumine Nilo.

é cercado pelo Oceano, pelo mar da Líbia, pelo rio Nilo.

20 Indica non magna minor arbore crescit arundo:

illius ec lentis premitur radicibus umor,

dulcia cui nequeant suco contendere mella. ${ }^{40}$

A cana indiana cresce não menor que uma grande árvore; a umidade é carregada por suas raízes flexíveis; a ela, os doces méis não poderiam rivalizar com [seu] sabor.

20 ${ }^{\mathrm{a}}$ schol. Bern. ad Lucani V 516: cum omnes harundinem dicunt, hic cannam dixit secutus Varronem, sicut et Ouidium. ${ }^{41}$

Escólio de Bernensia a Lucano $(5,516)^{42}$ : quando todos dizem caniço, este, que seguiu Varrão e, do mesmo modo, Ovídio, disse cana.

${ }^{40}$ Há algumas diferenças de grafia em Blänsdorf (2011, p. 238) e em Hollis (2007, p. 169, grifo nosso): "Indica non magna minor arbore crescit harundo; / illius et lentis premitur radicibus humor, / dulcia cui nequeant suco contendere mella." Em Courtney (2003, p. 252), a diferença só aparece em harundo.

${ }^{41}$ Em Blänsdorf (2011, p. 238), dicant. Este fragmento não aparece em Courtney (2003), nem em Hollis (2007).

${ }^{42}$ Sed sterili iunco cannaque intexta palustri, (Luc., 5, 516, grifo nosso); "Mas, no pantanoso estéril, trançada com junco e cana" (Tradução nossa). 


\section{Ephemeris: Notas}

$21-\cup \cup-\cup \cup-$ nubes ceu uellera lanae

stabunt $^{43}$

as nuvens ficarão como novelos de lã ${ }^{44}$

22 tum liceat pelagi uolucres tardaeque paludis

cernere inexpleto studio certare lauandi

et uelut insolitum pennis infundere rorem;

aut arguta lacus circum uolitauit hirundo ${ }^{45}$

et bos suspiciens caelum - mirabile uisu-

naribus aerium patulis decerpsit odorem;

43 “<- $\cup-\cup \cup \rightarrow$ nubes [sic] ut uellera lanae / constabunt" em Blänsdorf (2011, p. 239). Courtney (2003, p. 244) e Hollis (2007, p. 170) colocam "nubes si ut uellera lanae / constabunt".

44 "Amiúde, quando as chuvas se aproximam, primeiro / surgem nuvens muito semelhantes à lã," (Arat., 938-939, tradução de R. M. Brunhara, grifo nosso).

${ }^{45}$ Virgílio utiliza este mesmo verso em suas Geórgicas (2, 377). José Félix Pereira (1875, p. 19) traduz: "[...] a andorinha / Voa em torno dos lagos; [...]." Observe-se o tratamento dado aos mesmos temas que aparecem em Arato e em Varrão: "Os grous fogem dos vales; a bezerra, / Olhando para o ceo, os ares sorve / Com as ventas abertas; a andorinha / Voa em torno dos lagos; e nos charcos / As rans entoão as antigas queixas. / Mais vezes a formiga tira os ovos / Dos esconderijos por estreita via, / O grande arco celeste as aguas bebe, / E numeroso exército de corvos, / Largando o pasto, vae ferindo os ares, / Fazendo com as azas grande bulha. / Do mar já podes ver diversas aves / E as que pascem nos lagos deleitosos / Lá do Caystro junto aos campos de Asia, / Os hombros mergulham á porfia / Em copioso orvalho, oferecendo / Ás ondas as cabeças, ou saltando / Alegres sobre as águas, o desejo / Mostrando de lavar-se, mas inutil” (Verg., Georg., 1, 374-387). Em latim: “aëriae fugere grues, aut bucula caelum / suspiciens patulis captauit naribus auras, / aut arguta lacus circumuolitauit hirundo / et ueterem in limo ranae cecinere querelam. / Saepius et tectis penetralibus extulit oua / angustum formica terens iter et bibit ingens / arcus et e pastu decedens agmine magno / coruorum increpuit densis exercitus alis. / iam uariae pelagi uolucres et quae Asia circum / dulcibus in stagnis rimantur prata Caystri, / certatim largos umeris infundere rores, / nunc caput obiectare fretis, nunc currere in undas / et studio incassum uideas gestire lauandi." (Verg., Georg., 1, 374-387, grifo nosso). 
nec tenuis formica cauis non euehit oua. ${ }^{46}$

Então, em que seja permitido ver os pássaros do mar e do brejo modorrento competirem com insaciável desejo de [se] lavar e como que verterem o insólito líquido das penas; ou a arguta andorinha revoou ao redor do lago, e o boi, que contempla o céu - admirável vista -, apanhou com as amplas ventas o odor dos ares; e nem a delicada formiga não desloca os ovos nos buracos. ${ }^{47}$

\section{Belli Sequanici: Da Guerra Sequana}

\subsection{LIB. II: Livro II}

23 deinde ubi pellicuit dulcis leuis unda saporis. depois, quando a leve água de doce sabor atraiu.

${ }^{46}$ Blänsdorf (2011, p. 239) traz "cernere inexpletas studio certare lauandi" e "circumuolitauit", assim como a indicação de uma lacuna de nove versos após o quarto verso. Courtney (2003, p. 244) apresenta as mesmas alterações, embora só indique a lacuna, sem apontar quantos versos fariam parte dela. Hollis (2007, p. 171) endossa "inexpletas" e "circumuolitauit", mas não indica a lacuna.

47 "Amiúde, aves lacustres ou marinhas / banham-se avidamente, mergulhando nas águas, / ou em torno do lago andorinhas adejam por muito tempo / batendo a barriga na água, que começa a ondear, / ou aquelas mui infelizes progênies, alimento de cobras d'água, / pais de girinos, da água mesmo bradam, / ou solitário sapo coaxa ao romper da aurora, / ou, talvez, um corvo gralhador se enfie sob / a onda que chega na orla saliente / ou afunde-se em um rio da cabeça até a ponta / dos ombros, ou talvez até mergulhe por completo, / ou dê voltas perto da água, com rouco crocitar. / $\mathbf{E}$ os bois, logo antes de cair a água celeste, / erguem os olhos para o céu e sentem o cheiro do ar; / de suas ocas côncavas, as formigas trazem todos os seus ovos / rapidamente à superfície; [...]" (Arat., 942-957, tradução de R. M. Brunhara, grifo nosso). Cícero (Prog. fr. 4, 10-11 apud COURTNEY, 2003, p. 245) também teria traduzido a última parte dessa passagem: "mollipedesque boues, spectantes lumina caeli, / naribus umiferum duxere ex aere sucum."; "e os bois de pés delicados, que olham para a luz do céu, sorvem com as ventas a umidade do ar" (Tradução nossa). 


\section{Dubia: Duvidoso ${ }^{48}$}

SCHOL. Pers. 2, 36: alii uolunt Licinum tonsorem ac libertum Augusti Caesaris significari praediuitem, cuius monumentum est pretiosi operis uia Salaria prope urbem ad lapidem secundum. de hoc homine non inuenustum Varronis epigramma fertur:

marmoreo Licinus tumulo iacet, at Cato parvo,

Pompeius nullo: credimus esse deos?

Escólio em Pérsio $(2,36): 49$ outros quiseram ser dignificados como Licíno, barbeiro e liberto muito rico de César Augusto, cujo monumento, de precioso burilamento, está na via Salaria, próximo à urbe, junto à segunda pedra. Sobre esse homem, um epigrama de Varrão é relatado não sem elegância:

Licíno jaz em túmulo marmóreo, mas Catão, em humilde, Pompeu, em nenhum: acreditamos que os deuses existem?

\section{Referências}

APOLLONIO Rhodio. Os argonautas: poema de Apollonio Rhodio. Tradução de José Maria da Costa e Silva. Lisboa: Imprensa Nacional, 1852. Disponível em: https://books.google.pt/books?id=bC45AQAAM $\mathrm{AAJ} \&$ printsec $=$ frontcover $\& \mathrm{hl}=\mathrm{pt}-\mathrm{PT} \# \mathrm{v}=$ onepage $\& \mathrm{q} \& \mathrm{f}=$ false. Acesso em: 15 nov. 2017.

APOLLONIUS RHODIUS. Argonautica. Edited by George W. Mooney. Londres: Longmans, Green \& Co., 1912.

APOLÔNIO de Rodas. Las argonáuticas. Traducción de Manuel Pérez López. Madrid: Ediciones Akal, 1991.

\footnotetext{
${ }^{48}$ Este fragmento aparece apenas na edição de Blänsdorf (2011, p. 240) com numeração 24a. Gayraud (1971, p. 653) considera impossível que o epigrama pertença a Varrão, devido à incompatibilidade temporal, já que o poema não se referiria ao escravo de César, mas a um procurador na Gália, autor de uma célebre fraude.

49 "nunc Licini in campos, nunc Crassi mittit in aedis:" (Pers., 2, 36). Haroldo Bruno (1981, p. 112) traduz: “[...] ora para os campos de Licínio, ora para os palácios de Crasso: [...]."
} 
ARATO. Fenómenos. In: ARATO; GÉMINO. Fenómenos: Introducción a los fenómenos. Traducción de Esteban Calderón Dorda. Madrid: Editorial Gredos, 1993. p. 8-148.

ARATO. Fenômenos. Tradução de Rafael Matiello Brunhara et al. Cadernos de tradução, Porto Alegre, n. 38, p. 1-84, jan./jul. 2016.

BAEHRENS, Aemilius. Fragmenta poetorum romanorum. Lipsiae: Teubner, 1886. p. 332-336. Disponível em: https://archive.org/details/ fragmentapoetaru00baehuoft. Acesso em: 17 fev. 2016.

BLÄNSDORF, J. Fragmenta poetarum latinorum epicorum et lyricorum: praeter enni annales et ciceronis germaniciqve aratea. Göttingen: Hubert \& Co. GmbH \& Co. KG, 2011. DOI: https://doi. org/10.1515/9783110254495.

BRUNO, H. Pérsio: introdução, tradução e notas. 1981. 198f. Dissertação (Mestrado em Letras Clássicas) - Faculdade de Filosofia, Letras e Ciências Humanas, Universidade de São Paulo, São Paulo, 1981. Disponível em: http://www.teses.usp.br/teses/disponiveis/8/8143/tde14092016-121604/pt-br.php. Acesso em: 13 maio 2018.

COURTNEY, E. P. Terrentius Varro Atacinus. In: COURTNEY, E. The Fragmentary Latin Poets. Oxford: Oxford University Press, 2003. p. 235-253.

CROWTHER, N. B. Varro Atacinus: Traditional or Neoteric Poet?. L'Antiquité Classique, Bruxelles, v. 56, p. 262-268, 1987. DOI: https:// doi.org/10.3406/antiq.1987.2215. Disponível em: https://www.jstor.org/ stable/41656886. Acesso em: 02 abr. 2014.

EDWARDES, H.; WHELLER, G. B. The School and College Virgil, Æneids VII to XII: with English Notes. Dublin: S. J. Machen, 1845.

FLACCUS, Valerius C. C. Valeri Flacci Setini Balbi Argonauticon Libri Octo. Leipzig: Teubner, 1913.

FLACO, Gaio Valério. Cantos Argonáuticos. Tradução de Márcio Meirelles Gouvêa Júnior. Lisboa: Centro de Estudos Clássicos e Humanísticos, 2010. 
GAYRAUD, M. Un Narbonnais du Ier siècle avant J.-C.: le poète Varron de l'Aude. Bulletin de l'Association Guillaume Budé: Lettres d'Humanité, Paris, n. 30, p. 647-665, dez. 1971. DOI: https://doi. org/10.3406/bude.1971.4270. Disponível em: https://www.persee.fr/doc/ bude_1247-6862_1971_num_30_4_4270. Acesso em: 14 maio 2018.

HOLLIS, A. S. Fragments of Roman Poetry: c. 60 BC-AD 20. Oxford: Oxford University Press, 2007.

HORACE. Satyrarum libri. In: HORACE. The Works of Horace. Edição de C. Smart. Philadelphia: Joseph Whetham, 1836. v. II.

HORÁCIO. Sátiras. Tradução de Antônio Luís Seabra. Rio de Janeiro: Ediouro, [199-?].

LEE, M. O. Virgil as Orpheus: A Study of the Georgics. Nova Iorque: SUNY Press, 1996.

LUCANUS, M. Annaeus. Pharsaliae Libri X. Edição de Carolus Hermannus Weise. Leipzig: G. Bassus, 1835.

NATIVIDADE, E. S. Os Anais de Quinto Ênio: estudo, tradução e notas. 264f. 2009. Dissertação (Mestrado em Letras Clássicas) Faculdade de Filosofia, Letras e Ciências Humanas, Universidade de São Paulo, São Paulo, 2009. Disponível em: http://www.teses.usp.br/ teses/disponiveis/8/8143/tde-02022010-162128/pt-br.php. Acesso em: 14 maio 2018.

OVÍDIO. Amores. In: DUQUE, Guilherme Horst. Do pé à letra: os Amores de Ovídio em tradução poética. 263 f.2015. Dissertação (Mestrado em Letras) - Centro de Ciências Humanas e Naturais, Universidade Federal do Espírito Santo, Vitória, 2015. p. 68-172. Disponível em: http:// repositorio.ufes.br/bitstream/10/6777/1/Dissertacao\%20Guilherme\%20 Duque.pdf. Acesso em: 09 jun. 2018.

OVÍDIO. Obras: Os Fastos, Os amores e $A$ arte de amar. Tradução de Antônio Feliciano de Castilho. São Paulo: Cultura, 1943.

P. OVIDIUS Naso. Amores, Epistulae, Medicamina faciei femineae, Ars amatoria, Remedia amoris. Edição de R. Ehwald a partir de Rudolphi Merkelii. Leipzig: Teubner, 1907.

P. OVIDIUS Naso. Tristia. Edição de Arthur Leslie Wheeler. Cambridge, Mass.: Harvard University Press, 1939. 
PERSIUS. Juvenal and Persius with an English Translation. Edited and translated by G. G. Ramsay. Londres/Nova York: William Heinemann: G. P. Putnam's Son, 1918.

POLT, Christopher B. Allusive Translation and Chronological Paradox in Varro of Atax's Argonautae. American Journal of Philology, Baltimore, v. 134, n. 4, p. 603-636, 2013. DOI: https://doi.org/10.1353/ ajp.2013.0038. Disponível em: https://www.academia.edu/7104746/ Allusive_Translation_and_Chronological_Paradox_in_Varro_of_ Atax_s_Argonautae. Acesso em: 02 abr. 2014.

PRISCIANI. Institutionum Grammaticarum Libri I-XII. Edição de Martini Hertzii. In: KEILII, H. Gramatici Latini. Leipzig: Tebner, 1855. Disponível em: https://archive.org/details/ PriscianiInstitutionumGrammaticarumLibri. Acesso em: 15 maio 2018.

PROPÉRCIO. Tradução de Paulo Martins. In: MARTINS, P. O jogo elegíaco: fronteiras entre a cultura intelectual e a ficção poética. Nuntius Antiquus, Belo Horizonte, v. 11, n. 1, p. 137-172, 2015. Disponível em: http://www.periodicos.letras.ufmg.br/index.php/nuntius_antiquus/article/ download/8539/8666. Acesso em: 26 fev. 2017.

PROPERTIUS. Elegies. Edição de Lucian Mueller. Leipzig: Teubner, 1898.

QUINTILIAN. Institutio oratoria. Edição de Harold Edgeworth Butler. Cambridge, Mass.: Harvard University Press; Londres: William Heinemann Ltd., 1922.

QUINTILIANO. Livro X da Institutio oratoria. Tradução de Antônio Martinez Rezende. In: REZENDE, A. M. Rompendo o silêncio: a construção do discurso oratório em Quintiliano. 2009. $280 \mathrm{f}$. Tese (Doutorado em Estudos Linguísticos) - Faculdade de Letras, Universidade Federal de Minas Gerais, Belo Horizonte, 2009. p. 184-274. Disponível em: http://www.bibliotecadigital.ufmg.br/dspace/bitstream/handle/1843/ ALDR-7U8PNU/1432d.pdf? sequence=1. Acesso em: 09 ago. 2016.

RODRIGUES JÚNIOR, F. Aristos Argonauton: o heroísmo nas Argonáuticas de Apolônio de Rodes. 2010. 272 f. Tese (Doutorado em Letras Clássicas: Estudos Literários) - Departamento de Letras Clássicas e Vernáculas, Universidade de São Paulo, São Paulo, 2010. Disponível em: http://www.teses.usp.br/teses/disponiveis/8/8143/tde-28012011093845/pt-br.php. Acesso em: 11 jan. 2014. 
SÁNCHEZ, M. V.; PRENERÓN, I. V. Varrón Atacino, traductor de las Argonáuticas. Estudios Románicos, Murcia, v. 5, p. 1395-1401, 1989. Disponível em: http://revistas.um.es/estudiosromanicos/article/ view/80501/77741. Acesso em: 03 abr. 2014.

SENECA, el Viejo. Controversias: libros VI-X; Suasorias. Traducción de Ignacio Javier Adiego Lajara, Esther Artigas Álvarez e Alejandra De Riquer Permanyer. Madrid: Editorial Gredos, 2005.

SENECA, the Elder. The Elder Seneca: Declamations in Two Volumes. Edited by M. Winterbottom. Cambridge, Mass.: Harvard University Press, 1974.

VERGIL. Bucolics, Aeneid, and Georgics of Vergil. Edited by J. B. Greenough. Boston: Ginn, 1900.

VIRGÍLIO. As Geórgicas de Virgílio. Tradução de José Félix Pereira. Lisboa: Typographia Universal, 1875. Disponível em: https://archive. org/details/asgeorgicasdevir00virg. Acesso em: 18 mar. 2018.

VIRGÍLIO. Eneida. Tradução de José Victorino Barreto Feio e José Maria da Costa e Silva (livros IX-XII). São Paulo: Martins Fontes, 2004.

Recebido em: 16 de setembro de 2019. Aprovado em: 2 de dezembro de 2019. 